\title{
Evaluation of phosphorus pools and fractions in an acid tropical soil recapitalized with different phosphorus sources
}

\begin{abstract}
Bray 1 phosphorus (B1P) and sequential phosphorus (P) fractions were determined on soils treated with triple superphosphate (TSP), Gafsa (GPR), and Christmas Island phosphate rocks (CIPR), respectively, with and without manure. The fractions extracted in decreasing lability were iron oxide-impregnated paper strip $\mathrm{P}$ (Pi-strip $\mathrm{P}$ ), inorganic $(\mathrm{Pi})$, and organic $(\mathrm{Po})$ bicarbonate (NaHCO3-Pi and -Po), hydroxide [sodium hydroxide ( $\mathrm{NaOH})-\mathrm{Pi}$ and $-\mathrm{Po}$, hydrochloric acid $(\mathrm{HCl}) \mathrm{P}$, and residual (residue $\mathrm{P}$ ). The magnitude of $\mathrm{B} 1 \mathrm{P}$ was in the order TSP $>$ GPR=CIPR. Average B1P from PRs was two-fold the amount in TSP, whereas that of the fractions was $\mathrm{NaOH}-\mathrm{P}>$ Residue $\mathrm{P}<$ sodium bicarbonate $(\mathrm{NaHCO} 3) \mathrm{P}<\mathrm{Pi}$-strip $\mathrm{P}<\mathrm{HCl}$. Bray 1 extracted mainly the most labile fractions (Pi-strip $\mathrm{P}$ and NaHCO3-Pi), and plant $\mathrm{P}$ uptake was correlated mainly to $\mathrm{NaOH}-\mathrm{Po}$ and $\mathrm{NaHCO} 3-\mathrm{Pi}$. Magnitude of various fractions differed between TSP and PRs. Both B1P and the fractions were equally correlated to P uptake $\left(\mathrm{R} 2=0.38^{* *}\right)$. Nevertheless, sequential fractionation appears to be a powerful tool to identify the $\mathrm{P}$ status and availability in soil.
\end{abstract}

Keyword: Phosphorus fertilizer; Phosphorus pools and fractions; Recapitalization. 